\title{
El hombre metrosexual como Narciso contempo- ráneo: el papel del discurso publicitario actual en la construcción de la masculinidad
}

\author{
Olga HEREDERO DÍAZ \\ Universidad Complutense de Madrid \\ olga.heredero.diaz@ucm.es \\ Jennifer GARCÍA CARRIZO \\ Universidad Complutense de Madrid \\ jennigar@ucm.es
}

Recibido: 28/11/2014

Aceptado: 21/10/2015

\section{RESUMEN}

Existen diferentes definiciones del concepto de masculinidad. Por un lado están las normativas, que la entienden como lo que los hombres deberían ser y, por otro, los enfoques semióticos, que la definen como no-feminidad. Partiendo de este último enfoque y teniendo en cuenta que la feminidad ha evolucionado en los últimos años junto con la sociedad desdibujando la frontera entre lo que forma parte del rol femenino y lo que no, se puede afirmar que han surgido a partir de los renovados modelos de feminidad, diferentes y nuevas masculinidades entre las que se encuentra la del hombre metrosexual. Es en este tipo de masculinidad en concreto en la que se centra la presente investigación y en cómo se construye la narración de dicha masculinidad en el discurso publicitario actual recurriendo a la figura mítica de Narciso. Así, a partir de una revisión bibliográfica y de un análisis de contenido, se pretende analizar la influencia de la publicidad en la aparición del hombre metrosexual como nueva masculinidad en respuesta a la transformación de la feminidad, a la par que confirmar la presencia de la figura de Narciso como recurso en la construcción de la masculinidad en la publicidad actual.

Palabras clave: Masculinidad, sexualidad, publicidad, mito, narcisismo.

\section{The metrosexual man as the contemporary Narcissus: the role of current discourse of advertising in the construction of the masculinity}

\begin{abstract}
There are different definitions about the meaning of masculinity. On one hand, there are normative theories, which understand masculinity as men should be. On the other hand, semiotic approaches define it as non-femininity. Considering this second approach, it can be considered that femininity has evolved recently with society blurring the line between what is part of their role and what is not. From these renovated models of femininity, it could be argued the emergence of new and different masculinities such as the metrosexual man. It is in this particular kind of masculinity in which this research focuses, besides in how the narrative of that masculinity is constructed in the current advertising through the mythical figure of Narcissus. Thereby, after a literature review and a content analysis, the present study aims to analyze the influence of advertising in the emergence of metrosexual like new masculinity man as a result of the transformation of femininity. At the same time, it tries to confirm the presence of the figure of Narcissus as a resource in the construction of masculinity in today's advertising.
\end{abstract}

Keywords: Masculinity, sexuality, advertisement, myth, narcis. 


\section{Referencia normalizada}

Heredero Díaz, O.; García Carrizo, J. (2015). "El hombre metrosexual como Narciso contemporáneo: el papel del discurso publicitario actual en la construcción de la masculinidad". Documentación de las Ciencias de la Información, Vol. 38: páginas 245-263

\section{INTRODUCCIÓN}

Analizar la narración de las nuevas masculinidades, en concreto del hombre metrosexual, en la publicidad actual a través de la figura de Narciso implica a priori establecer una definición del término, seguida de una descripción de las nuevas masculinidades en relación con su concepción tradicional.

Entendida la masculinidad como la construcción social frente a lo femenino (enfoque semiótico), lo cierto es que su renovación es fruto de un proceso de adaptación a la transformación de la femineidad, tras los logros en la lucha por la igualdad entre ambos sexos. El resultado es un nuevo modelo de hombre, el metrosexual, en principio minoritario, pero que se masifica gracias a la capacidad amplificadora que sobre las tendencias sociales tiene la publicidad.

Surgen así nuevos consumidores varones representantes de una masculinidad alternativa a la tradicional y hegemónica en la sociedad machista y que son identificados por las marcas como un nicho de consumo a explotar. Para ello, recurren a la construcción de un discurso publicitario en el que se emplea el mito de Narciso para persuadir, en tanto en cuanto el relato publicitario reproduce historias que buscan la identificación del público con el personaje del spot, de forma que el consumo de los productos anunciados por esos Narcisos contemporáneos posibilita la transformación del consumidor en el protagonista del anuncio. Algo fundamental en un mercado como el actual en el que los productos adquieren diferenciación no por lo que son (valor de uso), sino básicamente por lo que simbolizan (valor simbólico).

De la reflexión sobre todo esto se podría concluir que la mitología se convierte en una fuente de inspiración a la hora de crear estereotipos, que una vez empleados por la publicidad, actualizan el mito reescribiéndolo sobre la base de un conjunto de arquetipos comunes al inconsciente colectivo de cada comunidad concreta.

Es por ello que el mito de Narciso está más íntimamente vinculado con la publicidad que cualquier otro de los relatos míticos. Narciso despertó el amor de todos por su extraordinaria belleza, pero sin corresponder a nadie se enamoró de sí mismo al ver su imagen reflejada en el río y, desesperado al no poder alcanzar el objeto de su amor ni satisfacer su pasión, permaneció junto al arroyo hasta consumirse.

Sucede lo mismo con los consumidores, que insatisfechos buscan saciar su narcisismo a través de las imágenes idílicas (casi míticas) que los anuncios les muestran. Es el triunfo de Narciso, un personaje de segunda categoría entre los mitos, que representa a la perfección los anhelos del metrosexual.

Si el mítico Narciso no se pudo resistir ante su imagen perfecta, el Narciso actual tampoco puede dejar de contemplarse constantemente. Una realidad que el mercado 
aprovecha satisfaciendo sus deseos con cientos de productos que supuestamente le harán más bello. El hermoso y joven Narciso ha caído en su trampa: saciar su propio ego, algo que nunca conseguirá, ya se encargará la publicidad de ello.

\section{OBJETIVOS}

Los objetivos específicos del presente estudio son, en primer lugar, analizar la influencia de la publicidad en la aparición del hombre metrosexual como una nueva masculinidad que se adapta a una femineidad renovada y, en segundo lugar, confirmar la presencia de la figura de Narciso como recurso en la construcción de la masculinidad en la publicidad actual. A partir de estos dos objetivos primarios se pretende establecer un concepto válido y completo de masculinidad/es, a la par que realizar un breve análisis del porqué de la inclusión del mito de Narciso en el discurso publicitario.

\section{METODOLOGÍA}

Desde el punto de vista metodológico, para alcanzar los objetivos planteados se ha optado por una revisión bibliográfica y por un análisis de contenido cualitativo. El punto de partida de esta investigación ha sido la definición del concepto de masculinidad, seguida de la enunciación de algunas de las teorías más relevantes sobre la existencia de una o múltiples masculinidades, así como del análisis de la transformación de su concepción tradicional en nuevas alternativas, como la del metrosexual, y de su representación en el discurso publicitario a través de la figura mítica de Narciso.

\section{CONTENIDO}

\subsection{Masculinidad vs masculinidades}

El interés de las ciencias sociales sobre la definición y el significado de la masculinidad tiene su origen en la publicación por Simone de Beauvoir en 1949 de El segundo sexo y ha sido creciente desde que en los años 50 la psicología social norteamericana se centrase en el análisis de los patrones de conducta de los sexos femenino y masculino, en principio, desde una perspectiva esencialista y heterosexista, según la cual es el sexo biológico del individuo el que determina su identidad.

Fue precisamente la distinción entre sexo y género el paso siguiente en las investigaciones sobre género, que según la definición de trabajo utilizada por la Organización Mundial de la Salud (OMS) "se refiere a los roles socialmente construidos, los comportamientos, actividades y atributos que una sociedad dada considera apropiados para los hombres y las mujeres".

Sin embargo, no sería hasta las décadas de los 70 y 80 cuando en Estados Unidos y en los países escandinavos su estudio se convirtiera en una especialización bajo el 
nombre de Men's studies, $y$ se tomara conciencia de que la masculinidad es un constructo histórico y cultural, de modo que la forma de ser hombre varía según el tiempo y la cultura, es más, incluso en una misma sociedad las maneras de serlo son múltiples y diversas interindividualmente, pero también intraindividualmente, puesto que van transformándose a lo largo de la vida de una misma persona (Téllez y Verdú, 2011) tal y como sostiene, entre otros, Michael Kimmel:

"La virilidad no es estática ni atemporal, es histórica; no es la manifestación de una esencia interior, es construida socialmente; no sube a la conciencia desde nuestros componentes biológicos; es creada en la cultura. La virilidad significa cosas diferentes en diferentes épocas para diferentes personas" (Kimmel, 1997: 49).

De hecho, el género se interioriza a través de un proceso de socialización que abarca, no solo la infancia, sino toda la vida del individuo (Sáez Buenaventura, 1990) $\mathrm{y}$, en consecuencia, todas las sociedades cuentan con categorías de género (masculino y femenino), pero no todas tienen un concepto de masculinidad entendida como "la posición en las relaciones de género, las prácticas por las cuales los hombres y las mujeres se comprometen en esa posición de género, y los efectos de estas prácticas en la experiencia corporal, en la personalidad y en la cultura" (Connell, 1997: 35).

Se trata de un planteamiento relacional según el cual el modo cómo se es hombre existe como contraposición a la femineidad, de manera que se podría distinguir entre las definiciones normativas que entienden la masculinidad como lo que los hombres debieran ser y, los enfoques semióticos, para los que la masculinidad es definida como no-femineidad.

Adoptando este último como punto de partida en esta investigación, resulta reveladora la existencia de muestras de la construcción por contraposición de las categorías occidentales de género ya en la Biblia, así como en otros relatos ágrafos o en la propia Torá (Díaz, 2006: 158-159):

"Dios dijo: hagamos al Hombre a nuestra imagen y semejanza. Domine sobre los peces del mar, las aves del cielo, los ganados, las fieras y los reptiles de la tierra" (Génesis, 1, 26).

"El Señor Dios dijo: No es bueno que el hombre esté solo, le daré una ayuda apropiada (...) será llamada Hembra porque ha sido tomada del hombre" (Génesis, 2, 18-23).

No obstante, hay autores como el antropólogo David Gilmore (1994), que aseguran que sí existe una masculinidad universal, de forma que es en los años 80 cuando se multiplican las investigaciones centradas en el análisis de su posible diversidad, dotando de fundamento empírico al enfoque relacional de la construcción social de lo masculino (Jociles, 2001). 
No sucede lo mismo desde el punto de vista teórico, según el cual los estudios de masculinidad oscilan entre los enfoques esencialistas, defensores de las diferencias biológicas y psíquicas entre los sexos como determinantes en las relaciones entre ellos (Edward O. Wilson, Lionel Tiger, Carl G. Jung, Thomas Moore o Keith Thompson), y los planteamientos constructivistas, que sostienen que las diferencias de género son productos culturales inexplicables exclusivamente a través de las características del sexo biológico (Margaret Mead).

Sin embargo, pese a la existencia de múltiples masculinidades, en toda cultura existe lo que se denomina masculinidad hegemónica, entendida como "la configuración de práctica genérica que encarna la respuesta corrientemente aceptada al problema de la legitimidad del patriarcado, la que garantiza (o se toma para garantizar) la posición dominante de los hombres y la subordinación de las mujeres" (Connell, 1997: 39). Aunque, lo cierto es que, cada sujeto varón, tiene la capacidad de decidir si está de acuerdo con los patrones de conducta impuestos o bien si prefiere ser hombre de manera diferente. En consecuencia, se puede concluir que no hay una, sino muchas masculinidades.

\subsection{De las masculinidades tradicionales a las nuevas masculinidades}

Aceptada la existencia de muchas formas en lo que a la construcción social del género masculino se refiere, lo cierto es que en la mayoría de las sociedades y culturas se puede hablar de una masculinidad hegemónica basada en la construcción de un modelo dual en el que coexisten los estereotipos femeninos tradicionales, que asignan a la mujer el rol de madre o esposa en base a su capacidad de "ser para otros negándose a sí misma", frente al "ser para sí mismos negando a los demás", propios del modo de ser hombre más tradicional y hegemónico.

Una masculinidad tradicional caracterizada por el individualismo a ultranza y el rechazo al otro/otra diferente (Bonino, 2000), que en el momento que se impone culturalmente y anula las alternativas, se convierte en estereotipo y modelo que sirve como instrumento de medida de la hombría del conjunto de los individuos varones.

Sin embargo, existen multitud de factores por los que no todos los hombres caben en este modelo (razones físicas, políticas, económicas, étnicas, sexuales, etc.) y que confirman que existen, además de la hegemónica, otras formas de ser hombre igualmente válidas.

Lo cierto es que si consideramos la masculinidad como:

"Una construcción cultural que se reproduce socialmente (...). Esa construcción se desarrolla a lo largo de toda la vida, con la intervención de distintas instituciones (la familia, la escuela, el Estado, la iglesia, los medios de comunicación, etc.) que moldean los modos de habitar el cuerpo, de sentir, de pensar y de actuar el género" (Faur, 2004: 54). 
Y que se erige por contraposición a la feminidad, sería lo lógico concluir que no se puede hablar de tal concepto sin tener en cuenta las relaciones entre hombres y mujeres y, en consecuencia, la forma de ser y actuar de éstas.

Es por ello que los cambios en los estereotipos tradicionales de las mujeres consecuencia de su lucha por la ansiada igualdad, han obligado a una transformación de la masculinidad tradicional, que pese a todo, no renuncia a su dominio sobre la mujer como evidencian la existencia de fenómenos como el "techo de cristal" (Bonino, 2000). No obstante, no se debe olvidar tampoco que la modificación del rol más tradicional del hombre requiere siempre de una transformación simultánea de las mujeres, puesto que la construcción de una masculinidad en igualdad de género basada en roles compartidos implica una deconstrucción del modelo masculino tradicional (Badinter, 1993).

$\mathrm{Y}$ es que la posmodernidad obliga a hombres y mujeres a asumir roles más adecuados a las nuevas demandas socioeconómicas, de modo que mientras en la antigüedad era propiedad del varón el control de lo público, en la actualidad es cada vez mayor su protagonismo en el ámbito privado.

Es el colofón a una larga lucha de las mujeres por la conquista de sus derechos y que se cobraba una de sus primeras víctimas en 1791, cuando Olimpia de Gouges, una luchadora de los Derechos Humanos fue guillotinada en París tras haber redactado la declaración de los derechos de la mujer, exigiendo la igualdad de ambos sexos ante la ley.

La batalla, primero, por los derechos políticos llevada a cabo por las sufragistas y que se extendería, después, al ámbito laboral y al doméstico, ha desencadenado una reorientación de género como condición esencial en la búsqueda de una sociedad igualitaria en derechos y obligaciones en la que la masculinidad hegemónica no tiene cabida.

Así, Rojas Marcos señala que el culto al "macho" ha servido históricamente para legitimar y reproducir la existencia del patriarcado mediante una "glorificación de sus privilegios" (Rojas, 2005), al que ha puesto fin el que los hombres tomaran conciencia del perjuicio que para su colectivo suponía el modelo tradicional de roles de género y del que ha intentado desvincularse con iniciativas como la fundación de movimientos como "Hombres por la Igualdad".

En resumen, nos encontramos ante una crisis de la forma hegemónica de ser hombre que en los últimos años ha propiciado la aparición de nuevas masculinidades que conviven con la más tradicional, siendo la figura del metrosexual la que ha cobrado un mayor protagonismo. Prueba de ello son las numerosas publicaciones de carácter tanto científico como divulgativo que han surgido sobre el tema, entre ellas, The metrosexual guide to style (Flocker, 2003), publicado en España en abril del año siguiente $o$ el libro de Pedro Palao y Olga Roig (2004), Del macho ibérico al metrosexual. El nuevo hombre está llegando, cuyo texto de presentación no deja lugar a dudas de la transformación en curso: 
"El machote pichabrava de semáforo; el chulo piscinas paellero; el barrigón cervecero que hace trajes de saliva a las mujeres que pasan a su lado, son historia. Hay un nuevo hombre en la ciudad: urbano, culto, delicado, femenino, sensual y hetero. Ha llegado el

METROSEXUAL.

El nuevo hombre del siglo XXI es un profesional independiente, liberal, adinerado y joven que vive en las grandes urbes. Se ama por encima de todas las cosas. Cuida su imagen y es capaz de distinguir con los ojos cerrados la diferencia entre One, de Calvin Klein, y Envy, de Gucci.

Un modelo anglosajón que ha tardado en llegar a España pero que está arrasando, no sólo entre los hombres, sino también entre las mujeres. Un modelo que, en contacto con el macho ibérico tradicional, ha dado paso a un nuevo fenómeno: el METROSEXÍBERO.

¿Qué son y cómo han evolucionado? ¿Qué tienen de metrosexíbero: José Luis Rodríguez Zapatero, José Coronado, Miguel Ángel Muñoz, Antonio Resines, Eloy Azorín, Florentino Fernández, Coto Matamoros, Miguel Bosé o Xavier Sardá? Para salir de dudas y saber a qué nuevo espécimen nos estamos enfrentando, es imprescindible leer atentamente este libro”. (Téllez y Verdú, 2011: 96-97).

Y es que si la mujer se había masculinizado adoptando los perfiles y atributos de éxito que estaban representados por los hombres, el metrosexual reacciona ante la transformación femenina apostando por la igualdad al decidir utilizar sus mismas armas: erotismo, belleza y seducción.

\subsection{Las nuevas masculinidades como nicho de consumo: el papel de la publicidad}

Son cada vez más los autores que al innegable papel de la publicidad como instrumento de persuasión con fines comerciales añaden también su carácter "socializador", puesto que la publicidad "asume una función social, reforzando el sistema socioeconómico; su acción no se restringe al ámbito comercial, ya que genera prejuicios, necesidades, expectativas, $y$, además de productos, vende también modelos de vida y de relaciones sociales" (Feliu, 1984:68).

Una capacidad de socialización dual, que sirve para dar visibilidad a modelos sociales minoritarios a modo de catalizador de tendencias emergentes y "acelerador del cambio social” (Feliu, 2009) y para perpetuar los modelos dominantes. Esto último lo consigue recurriendo una y otra vez al uso de estereotipos, ya que "en el proceso comunicativo en que se integra el anuncio publicitario, los mensajes son susceptibles 
de transmitir estereotipos (...) y contribuir a su mantenimiento” (Berganza y Del Hoyo, 2006: 173).

La publicidad actúa, por tanto, no solo como reflejo fiel de la sociedad que la produce, sino como "regulador del cambio social”. Y así es como en la década de los 90 surgen campañas con temas hasta entonces ignorados (Gámez y otros, 2003), de forma que nuevas realidades como los malos tratos, la diversidad racial o grupos sociales como gays, lesbianas o personas con discapacidad se integran en el discurso publicitario. Y, por supuesto, las transformaciones en los roles de género no son ajenas a dicho fenómeno, de forma que los nuevos modelos masculinos se convierten en contenido publicitario.

En este sentido, autores como González i Paredes señalan el declive de los atributos masculinos más tradicionales, que a día de hoy se vinculan con la violencia machista, la discriminación de género y la agresividad, mientras que:

"la mujer se muestra como la esperanza de un futuro mejor, del desarrollo sostenible, del cuerpo ecológico, de la encarnación de la efectividad, y sus estereotipos históricos como la sentimentalidad, la empatía, el gusto por los detalles o la sexualidad difusa se muestran como verdaderos atributos para el siglo XXI” (González i Paredes, 2004: 31).

En consecuencia, y dado que la publicidad hace tiempo que optó por dejar de mostrar los productos y sus usos y comenzar a plasmar el estilo de vida y a quiénes los consumen, las nuevas alternativas de cómo ser hombre cobran interés y protagonismo publicitario, puesto que poseen muchas de las cualidades mejor valoradas por la sociedad actual. Interés porque se trata de hacer hincapié en la creación de necesidades simbólicas que conforman la identidad del individuo en función del "eres lo que tienes o lo que llevas puesto" y, protagonismo publicitario, porque se reelaboran junto al proliferar de nuevas masculinidades los tipos de hombre ideal correspondientes, que no pueden permanecer ajenos a la presión del consumo como sostén del sistema de producción postfordista, y que tienen su reflejo en una publicidad que impulsa la comercialización de los atributos icónicos de estas nuevas masculinidades.

El resultado es que la incorporación de la mujer a la vida pública y laboral obliga al hombre a replantearse su rol; una crisis de identidad que finalmente resuelve prestando más atención a los aspectos formales, de manera que es su interés por su imagen lo que mitiga su inseguridad por la indefinición de su rol como hombre. Este es el origen de la aparición de las nuevas masculinidades, "una tendencia que se inicia en los años 80 y que paulatinamente se ha ido extendiendo, gracias al interés de las empresas y la insistencia de la publicidad” (Rey, 2009: 10), pese a que se pueden citar como antecedentes las figuras del petimetre, el dandi, el gentleman o el galán de cine (López, 2005).

No obstante, los anteriores eran grupos minoritarios y no es hasta 1986, con la publicación del estudio de Pascale Weil, Et moi, emoi. La commnication publicitaire 
face à l'individualisme cuando se pone de manifiesto la aproximación entre hombre y mujer, tanto en su interés por su imagen como en su rol social.

Surge entonces un nuevo hombre, que patrocinado por la publicidad y los medios de comunicación, se consolida en una nueva masculinidad: el metrosexual. Un término acuñado en 1994 por el periodista inglés Mark Simpson en Independent on Sunday refiriéndose a un nuevo perfil de varón: "un caballero narcisista enamorado no sólo de sí mismo sino también de su estilo de vida" y, al que en julio de 2002, en su artículo "Meet the metrosexual". El término procede de la unión de "metro", por ser el nuevo hombre habitante de las metrópolis contemporáneas y "sexual”, aludiendo a su exacerbado lado femenino (Rey, 2006) y el periodista lo definía como:

"un joven con dinero para gastar, que vive en la ciudad, donde están las mejores tiendas, clubs, gimnasios y las mejores peluquerías. Puede ser oficialmente gay, hetero o bisexual, pero esto no tiene tanta importancia porque se ve a sí mismo como su propio objeto de deseo y placer. De profesiones liberales como modelos, medios de comunicación y productoras o músicos pop y, ahora, también deportistas, saben que atraen, aunque la verdad sea dicha, lo mejoran con productos cosméticos masculinos" (Simpson, 2002).

El término se extendió tan rápidamente gracias a los medios de comunicación y la publicidad que fue designado palabra del año 2003 por la American Dialect Society de Washington (Díaz, 2006), aunque como “el vocab lo más ultrajante” (Retico, 2004: 36).

De esta forma, una nueva figura masculina se imponía gracias a su protagonismo en los medios y la publicidad. Y es que el metrosexual es la generalización de un modelo de hombre, minoritario en los 80 , pero que se convierte en protagonista a comienzos del nuevo milenio debido a factores sociales, culturales, económicos y empresariales y de la mano de una agencia de publicidad, en tanto en cuanto se ha transformado en un público objetivo que hay que conquistar, en un nicho de consumo a explotar. En palabras de Juan Rey: “(...) el "metrosexual” es un nuevo modelo (para los jóvenes) y un nuevo cliente (para las empresas)” (Rey, 2006: 22).

No es de extrañar entonces que fuese el grupo neoyorquino de publicidad y marketing Euro RSCG Worldwide, quién en 2003 puso de relieve su gran potencial como segmento de consumo, lo que harían después en España las principales revistas del sector publicitario: Gemma Cernuda i Canelles con su artículo "Marca metrosexual. El hombre que hace cosas de mujeres" publicado en la revista Control de enero de 2004 o Elvira Esparza en el número de la segunda quincena de junio en El Publicista, con el título "A la caza del metrosexual", donde le señala como un grupo social prioritario para los publicitarios por su elevado nivel de consumo (Esparza, 2004).

Un interés que se traslada a los medios de comunicación generalistas, como evidencia el documental emitido por Canal + en junio de 2004 titulado "Metrosexual” y 
que muestra cómo es este nuevo tipo de hombre, cómo viste, cómo vive y cuáles son sus gustos y los referentes mediáticos que mejor lo representan.

En definitiva, todos estaban de acuerdo en lo importante que resultaba la aparición de un consumidor tan cualificado para la economía:

"Lo cierto es que para economías como la nuestra, los metrosexuales son sujetos deseables a los que hay que promover, porque no es casualidad que todo lo que usan o se ponen encima redunda en millones de pesos de ganancia para las empresas de moda y cosméticos que ven ante sus ojos un nuevo nicho de consumo" (Arancibia, 2004: 48).

Y una vez identificado el target y sus deseos y necesidades, el siguiente paso fue ofrecerle a través de la publicidad, un producto que lo transformara en "un hombre joven, hermoso, con un cuerpo bien alimentado y bien moldeado, hidratado y perfumado, luciendo unos complementos exclusivos, vistiendo una indumentaria elitista, conduciendo un coche de marca..." (Rey, 2009: 7), sobre todo porque "(La publicidad) Formaliza precisamente la positividad de la vida y, mediadamente, del producto. Los valores típicos de la publicidad son siempre de carácter positivo y su narración es siempre una lucha con lo negativo." (González, 1999: 7)

Sin embargo, lo cierto es que el protagonismo del metrosexual duró poco y en 2005, Mariam Salzman, vicepresidenta por entonces de la agencia de publicidad Walter Thompson, publicaba El futuro del hombre, un libro en el que describía la nueva masculinidad que relevaba al metrosexual: el übersexual. Un nuevo modelo de hombre más moderado en lo que a su parte femenina se refiere, menos banal y más comprometido socialmente y con el que la industria publicitaria pretendía captar a aquellos segmentos de consumidores que rechazaban al metrosexual por no identificarse con su exacerbada femineidad.

Una forma de ser hombre que se está viendo sustituida por la figura del lumbersexual1, sujetos que "aunque trabajen para una empresa de software parecen recién salidos del bosque: su barba es frondosa, usan botas y camisa de leñador. El hombre "lumbersexual" está desplazando con su estilo salvaje al metrosexual en el paisaje urbano" (AFP, 2014). Un hipster "supuestamente" desaliñado que a modo de leñador urbano invade las calles de las ciudades y que prefiere la vida al aire libre al cuidado del cuerpo en el gimnasio, pero sin que por ello dejen de estar constantemente preocupados por su aspecto. Los actores norteamericanos Joe Manganiello o Vincent Gallo, el canadiense Ryan Gosling o el británico Gerard Butler, son probablemente, lumbersexuales.

${ }^{1}$ El término es el resultado de la combinación de "lumber" y “sexual”, lo que podría traducirse literalmente como "leñasexual". 
Sea como fuere, la aparición del metrosexual, primero, del übersexual, después y, del lumbersexual, recientemente, responde:

"a la masificación de un viejo modelo minoritario (el hombre bello), convertido en mayoritario debido a la concurrencia de diversos factores: la implantación de la sociedad de consumo, la necesidad de expansión de las empresas de moda y cosmética ante la saturación del mercado femenino, y la consiguiente presión publicitaria con el objetivo de ampliar el mercado masculino" (Rey, 2009: 12).

Es el interés económico de las empresas cuyos productos demandan estos perfiles de hombre, en principio minoritarios, el que hace que se conviertan en protagonistas del discurso publicitario, amplificando su presencia en una sociedad para la que se consolidan como nuevas formas de ser hombre.

En conclusión, la publicidad contribuye al sueño narcisista de las nuevas masculinidades creando un escenario donde el individuo puede encontrar los objetos de consumo, con los que pretende consolidar la imagen que desea proyectar de sí mismo al exterior, al tiempo que alimenta sus fantasías de ser como los modelos que le incitan a usar esos productos, aunque solo sea por unos segundos. De hecho, lo más preocupante es que su interés desmedido por su apariencia externa no es el resultado de una decisión personal, sino de una imposición determinada por factores socioeconómicos en la que la publicidad tiene mucho que decir.

La consecuencia es que el hombre ha dejado de estar en un segundo plano y se ha convertido en coprotagonista del discurso publicitario junto a la mujer.

\subsection{La figura de Narciso como recurso del discurso publicitario en la construcción de las nuevas masculinidades}

Es obvio que la publicidad cumple una función comercial y, tal como ya se ha señalado, actúa como regulador del cambio social; en uno y otro caso, recurre a los estereotipos como estrategia para minimizar el tiempo que el público necesita para comprender el mensaje, de ahí que sean muy numerosos los estudios dedicados al análisis de los modelos de hombre y mujer presentes en la publicidad.

En concreto, la investigación sobre los estereotipos y la representación de las mujeres y los hombres en la publicidad de televisión se remonta a los años 70 en Estados Unidos, mientras que en España, una de las pioneras fue la realizada por María Luisa Balaguer en 1985, que identifica 5 tipos de mujer (mujer ama de casa, mujer trabajadora, mujer belleza (objeto), mujer inferior al hombre y mujer valor asociado a un producto) y 4 estereotipos de hombre en la publicidad española (el ejecutivo, el hombre en la casa, el hombre con sus hijos y el hombre conquistador). 
Unos años después, sería Juan Rey el que tras su investigación afirmase la cada vez mayor indefinición de los papeles del hombre y la mujer en el discurso publicitario debido a la incipiente presencia de nuevas masculinidades, como la del hombre metrosexual (Rey, 1994). Por su parte, Manuel Garrido recoge la existencia de otros estudios que consolidan este área de análisis en España, como los de Martín Serrano, 1995; González-Solaz y García-Cubells, 2000; Correa, Guzmán y Aguaded, 2000; etc. (Garrido, 2007), para citar después a Mitoanálisis de la publicidad, de José Luis León (2001) como la obra más destacada sobre la cuestión.

Todos confirman cómo la evolución de la representación de los modelos de hombre y mujer ha ido pareja a los roles sociales que han desempeñado. Así, por ejemplo, en la publicidad española del Franquismo y hasta finales de los años 80, el discurso publicitario muestra una masculinidad tradicional, siendo el hombre el protagonista de la vida social, puesto que trabaja fuera de casa, es el sostén económico de la familia y, por tanto, toma las decisiones de consumo importantes. La mujer, por el contrario, se desenvuelve como madre y esposa perfecta y, en ocasiones, como objeto de deseo para el varón.

Conforme se suceden los años y tiene lugar la conquista de las mujeres del espacio público y la participación de los varones en la esfera privada, la publicidad se transforma para adaptarse y transmitir una imagen mucho más igualitaria.

Un discurso publicitario en el que el hombre se incorpora a aquellos ámbitos que parecían propios de la mujer y en el que consume productos hasta entonces destinados a ella (perfumería, cosmética, etc.).

Estas transformaciones son causa y a la vez consecuencia de la aparición de nuevas construcciones del género masculino, entre ellas la del hombre metrosexual, que se incorpora al relato publicitario de una sociedad en la que la imagen del hombre en la publicidad está cada vez más ligada al mercado de la belleza y que recurre para su consolidación a la figura mítica de Narciso.

"Del "Mens sana in corpore sano" se ha pasado, parafraseando la máxima jesuítica, al "Ad maiorem corporis gloriam". Ya no importa la mente, el espíritu, ahora todo se hace para mayor gloria del cuerpo (indumentaria, alimentación, deporte y cosmética). Resulta así que el nuevo hombre es, como el héroe de Italo Calvino, un sujeto demediado, compuesto sólo de un cuerpo al que ama y mima con una pasión narcisista (...)” (Rey, 2006: 25).

Un mito representado en multitud de ocasiones a lo largo de la historia del Arte $^{2}$, pero que ha adquirido un renovado protagonismo, quizá por el auge actual del culto a

2 Cellini en 1540, Caravaggio en 1545, Poussin en 1627, Cossiers en 1645, Moreau en 1881, Waterhouse en 1903 o Dalí en 1936, son algunos de los artistas con obras dedicadas al joven Narciso. Referencias a 
la imagen o por el hecho de que la figura de Narciso se haya utilizado como icono de la comunidad gay. Un ejemplo paradigmático, es la campaña "Cuerpos Danone”, que en 1991 utilizaba como reclamo el cuerpo masculino.

Lo cierto es que el hombre metrosexual se configura gracias al discurso publicitario como un Narciso contemporáneo, que busca el placer en el consumo de objetos como vía de escape de sí mismo. Un sujeto hedonista y ensimismado con su reflejo en el espejo de la publicidad, que le muestra la imagen de un sujeto bello, perfecto e idealizado estéticamente. Así, "para la publicidad actual, ser hombre ha comenzado a significar ser bello, joven y tener un cuerpo acorde el canon imperante" (Rey, 1994: 188).

Para ello recurre a los iconos del momento, deportistas, cantantes y actores, como Brad Pitt, David Beckham o Cristiano Ronaldo, que como símbolos mediáticos representan valores como la masculinidad, la competitividad, el triunfo y el éxito social, relacionados con una profesión que les proporciona ingresos millonarios (López, 2005). Una muestra de ello es la campaña internacional de Pepsi "Foot battle" (2004)3, que protagonizaban los jugadores de fútbol David Beckham, Roberto Carlos, Raúl, Ronaldhino y Totti, y en la que transformados en héroes medievales, liberaban a las aldeas de los saqueadores de los mercados.

Sin embargo, el individuo narcisista ni siquiera se ama a sí mismo; al igual que Narciso está enamorado del reflejo que le devuelve, en este caso, la publicidad, lo que conduce a su deshumanización y transformación en un individuo hedonista, materialista e individualista. La campaña de Nike Football de 2010, "El adversario de Cristiano"4, muestra a un Cristiano Ronaldo obsesionado por la perfección y enamorado de su reflejo ("adoro a ese tipo", manifiesta en un momento del spot); un ser ensimismado, exigente consigo mismo y altamente competitivo.

Son los peligros de esta nueva masculinidad, que autores como Enrique Rojas o Juan Rey pusieron de manifiesto de forma temprana. Un nuevo discurso publicitario que transforma al sujeto en un hombre light:

“(...) individuo caracterizado por el narcisismo y el subjetivismo; centrado en sí mismo, en su personalidad y en su cuerpo, con un individualismo atroz, desprovisto de valores morales y sociales, $y$

Narciso se hayan también en la obra de Alfonso X el Sabio, Petrarca o en la poesía lírica medieval, sin olvidar la reinterpretación del mito en El retrato de Dorian Gray de Oscar Wilde.

3 El spot creado en el año 2004 por la agencia CLM BBDO puede visualizarse en www.youtube.com/watch?feature=player_detailpage \&v=Z7UbK24ZPc0

4 La versión completa del spot está disponible para su visualización en www.youtube.com/watch?v=kuN1yO_wL4I\&feature=relmfu 
además desinteresado por cualquier cuestión trascendente" (Rojas, 1998: 88).

Un esclavo de su imagen que se convierte en un hombre objeto:

"La aparición del hombre objeto ha supuesto que éste automáticamente adopte y adapte algunas características de su predecesora, una de las cuales, quizás la más importante, sea el hecho de ser bello, porque en publicidad ser bello es condición indispensable para existir, ya que la belleza es sinónimo de éxito profesional, triunfo personal, aceptación social y afán tanto de gustar, como de gustarse" (Rey, 1994: 190).

La sociedad, los medios de comunicación y el discurso publicitario le ofrecen al hombre light modelos ideales para merecer ese reconocimiento que siempre busca, pero que depende de una perfección imposible de alcanzar, frustrando todas sus ilusiones. Pero al mismo tiempo la publicidad le consuela generando nuevas expectativas en lo que a alcanzar su ideal se refiere, mostrándole nuevos productos que le ayudarán a conseguirlo.

$\mathrm{Y}$ recurrir al mito de Narciso es una buena estrategia. El motivo es que los mitos han sido y son esenciales para el hombre porque son manifestación de una de las actividades características del ser humano y que es básica para su conformación como ser racional y social: la construcción de relatos.

Por ello, los mitos no han desaparecido en la época actual, sino que ahora se renuevan a través de diferentes medios, como por ejemplo, la publicidad. Y es que son relatos que nos conducen a una dimensión íntima y reconocible, siendo precisamente este carácter reconocible lo que les convierte en un recurso publicitario ideal.

Existe, por tanto, una parte de información no visible y que se oculta en el inconsciente a la que la publicidad apela para hacerla consciente y reproducir comportamientos de compra; la herramienta para hacerlo es el mito. En este sentido la publicidad emplea el mito para persuadir, puesto que al referirse éste a formas simbólicas universalmente reconocidas es más fácil llegar al inconsciente del público y estimular así el consumo.

En consecuencia, se puede afirmar que las imágenes publicitarias contienen un simbolismo que los mitos nos ayudan a descifrar, al mismo tiempo que la publicidad actualiza el mito. Un ejemplo es el spot "Espejos" de Toyota Yaris ${ }^{5}$, realizado por DDB El Salvador en 2005, en el que un objeto, el coche en este caso, se antropomor-

5 La versión completa del spot está disponible para su visualización en www.youtube.com/watch?v=q1YkSffWj_0\%20 
fiza para transformarse en un Narciso de cuatro ruedas que busca su reflejo en el mobiliario urbano mientras recorre la ciudad.

Así, emplear el mito de Narciso como recurso publicitario en la construcción de las nuevas masculinidades, en concreto de la figura del metrosexual, se justifica por ser Narciso un personaje complejo que simboliza el culto a sí mismo, al cuerpo y a la belleza, de forma que si Narciso no se pudo resistir ante su imagen perfecta, el Narciso de hoy tampoco puede dejar de contemplarse, generándole el mercado una ansiedad infinita por alcanzar una perfección estética que viene dada por el consumo de determinados productos, lo que aprovechan las marcas para posicionarse en su mente de consumidor y formar parte de su short list.

$\mathrm{Y}$ es que "el nuevo hombre, el que se preocupa de asuntos catalogados como femeninos, sin dejar de ser hombre, es un sujeto social y una construcción publicitaria” (Rey, 2006: 19).

En definitiva, la publicidad actual revisita el mito de Narciso una y otra vez para comercializar una extensa variedad de productos, haciendo del metrosexual perfecto que los anuncia un objeto de consumo estético y erótico; el reflejo, cual Narciso contemporáneo, con el que el hombre de hoy se identifica y del que no puede sustraerse.

\section{CONCLUSIONES}

En este artículo y desde un enfoque semiótico, que entiende la masculinidad como no-femineidad, se propone la existencia de múltiples masculinidades que varían de acuerdo al momento histórico, la ubicación geográfica, la cultura y la sociedad.

Sin embargo, en toda sociedad existe una forma de ser hombre dominante, que en el caso de las sociedades occidentales y hasta hace apenas unas décadas, se correspondía con la masculinidad tradicional y, que ante el empuje de las conquistas feministas, se ha visto obligada a abandonar el modelo propio de la sociedad machista, en la que el ideal era el varón fuerte y poco sensible que dominaba a una mujer cuyas aspiraciones se reducían a ser la esposa y madre perfecta, para evolucionar dando lugar a nuevas masculinidades.

Surge así un renovado modelo de hombre que se adapta a los logros de la mujer en una sociedad más igualitaria, apropiándose de los atributos que hasta entonces le estaban reservados a la mujer. Es el hombre metrosexual, un nuevo Narciso, sofisticado y hedonista, que al poco tiempo será sustituido por el übersexual, que hoy se ve amenazado por el lumbersexual.

Así, de lo recogido en las páginas precedentes es posible concluir que las tres variantes son creaciones comerciales, nuevas formas de ser hombre que solo en el caso del metrosexual sirve para dar nombre a un target ya existente. Pero tampoco se puede obviar que es la publicidad la que le da visibilidad y lo consolida como una nueva construcción social del género masculino, gracias a su capacidad amplificadora para convertir corrientes minoritarias en fenómeno de masas (efecto boomerang). 
Lo cierto es que pese a que los estudios sobre la representación de la masculinidad y feminidad en la publicidad se han incrementado en las últimas décadas, no se ha realizado aún ningún análisis en profundidad sobre la representación del papel del hombre en el discurso publicitario, a excepción de los ya citados estudios de Juan Rey. No obstante, es evidente que ha habido una transformación de la representación de hombres y mujeres en el discurso publicitario, de forma que la distribución de los roles es mucho más igualitaria. Esta feminización publicitaria no es ajena a la feminización social del hombre, al contrario, es consecuencia de los cambios sociales derivados de la conquista de derechos por parte de la mujer, que obligaron a una redefinición de géneros.

Una asimilación por el hombre de atributos otrora femeninos que tiene su reflejo en el discurso publicitario mediante la incorporación al mismo de las nuevas masculinidades, gracias, entre otros, a la utilización de la figura mítica de Narciso.

Así, la publicidad incluye una serie de estructuras míticas para lograr una comunicación eficaz y emocional con los consumidores y, es en este contexto, donde el uso de Narciso, un ser bello que encuentra el placer en la contemplación de su propio reflejo, cobra sentido.

$\mathrm{Y}$ es que las nuevas masculinidades son el resultado de las reivindicaciones feministas que, aunque no hayan conseguido modificar sustancialmente los estereotipos femeninos que se incluyen en la publicidad, han logrado un pequeño triunfo al introducir el arquetipo masculino de Narciso en el discurso publicitario.

\section{BIBLIOGRAFÍA}

ARANCIBIA, Nicolás. (2004, 4 de febrero). «Metrosexual: ¿un metro de qué?», La Nación, 2004, 4/02, 48.

BADINTER, Elisabeth: XY: la identidad masculina. Madrid, Alianza, 1993, 256 págs. Balaguer Callejón, María Luisa: La mujer y los medios de comunicación de masas. El caso de la publicidad en televisión. Málaga, Arguval, 1985, 119 págs.

BERGANZA CONDE, María Rosa y DEL HOYO HURTADO, Mercedes. «La mujer y el hombre en la publicidad televisiva: imágenes y estereotipos», Zer, 2006, 21, 161-175 (eciencia.urjc.es/bitstream/10115/3266/3/zer21_14_hoyo.pdf.txt) Consulta: 23-9-2014.

BONINO, Luis. «III. Varones, género y salud mental: deconstruyendo la "normalidad” masculina», Nuevas masculinidades, 2000, 2, 41. (http://bivir.uacj.mx/Reserva/Documentos/rva2006176.pdf) Consulta: 24-9-2014.

CERNUDA I CANELLES, Gemma. (2004). «Marca metrosexual. El hombre que hace cosas de mujeres», Control, 2004, 498, 61.

CERVANTES PACHECO, Ericka Ivonne. «La nueva masculinidad, el significado de ser hombre, padre, esposo e hijo en la posmodernidad». Revista de Psicología Uaricha, 2005, 4, 58-60 (www.revistauaricha.umich.mx/Articulos/Uaricha_04_058060.pdf) Consulta: 23-9-2014. 
CONFEDERACIÓN DE ADOLESCENCIA Y JUVENTUD DE IBEROAMÉRICA, ITALIA Y EL CARIBE. (2009). El varón como factor de riesgo: Masculinidad, salud mental y salud reproductiva. Perú, CODAJIC, 2009 (www.codajic.org/sites/www.codajic.org/files/El\%20varon\%20como\%20factor\% 20de\%20riesgo_0.pdf) Consulta: 17-9-2014.

CONNELL, Raewyn (1997). La organización social de la masculinidad. En Valdés, Teresa y Olavarría, José (Eds.): Ediciones de las Mujeres 24. Masculinidad/es. Poder y crisis. Santiago de Chile, Isis Internacional-Flacso Chile, 1997, pp. 31-48 (www.engagingmen.net/files/resources/2010/EME/organizacion_social_masculini dad.pdf) Consulta: 27-9-2014.

DÍAZ DIEGO, José. (2006). «La ilógica de los géneros: metrosexuales, masculinidad y apoderamientos». Revista de Antropología Iberoamericana, 2006, 1, 157-167 (www.aibr.org/antropologia/01v01/articulos/010109.pdf). Consulta: 23-9-2014.

ESPARZA, Elvira. «A la caza del metrosexual». El Publicista, 2004, 106, 29-32.

FAUR, Eleonor: Masculinidades y Desarrollo Social. Las relaciones de género desde la perspectiva de los hombres. Colombia, UNICEF, Arango editores, 2004 (www.unicef.org/colombia/pdf/masculinidades.pdf) Consulta: 24-9-2014.

FELIU ALBADALEJO, Ángeles. Publicidad y cambio social. Nuevas realidades, ¿nuevos discursos?. En: Comunicación, Memoria, historia, modelos. Madrid, Edipo, 2009, pp. 396-406 (rua.ua.es/dspace/bitstream/10045/15818/1/Binder6.pdf) Consulta: 24-9-2014.

FELIU GARCÍA, Emilio: Los lenguajes de la publicidad. Alicante, Universidad de Alicante, 1984, 72 págs.

FLOCKER, Michael: The Metrosexual Guide to Style: A Handbook for the Modern Man. Boston, Da Capo Press, 2003, 208 págs.

GÁMEZ FUENTES, M.J., RIVAS MACHOTA, A.M. y SALMERÓN SÁNCHEZ, P. La masculinidad embotellada: la publicidad de perfumes masculinos ante los nuevos discursos sociales. En: La comunicación: nuevos discursos y perspectivas. Madrid, Comunicación 2000, 2003, pp. 375-380.

GARRIDO LORA, Manuel. (2007). «Estereotipos de género en la publicidad». $\begin{array}{llll}\text { Creatividad } & \text { y } & \text { Sociedad, } & 2007,\end{array}$ (www.creatividadysociedad.com/articulos/11/Creatividad\%20y\%20Sociedad.\%20 Estereotipos\%20de\%20ge\%CC\%81nero\%20en\%20la\%20publicidad.pdf) Consulta: 23-9-2014.

GILMORE, David: Hacerse hombre: concepciones culturales de la masculinidad. Barcelona, Paidós, 1994, 256 págs.

GONZÁLEZ I PAREDES, Jordi: Usos actuales del marketing sensual. Iconos femeninos en la publicidad de hoy. Barcelona, Granica, 2004, 86 págs.

González Solas, Javier. Arte y publicidad: la estrategia de la sustitución (pendientedemigracion.ucm.es/centros/cont/descargas/documento3045.pdf) Consulta: 26-9-2014. 
JOCILES RUBIO, María José. (2001). «El estudio sobre las masculinidades. Panorámica general». Gazeta de Antropología, 2001, 17, artículo 27 (www.ugr.es/ pwlac/G17_27MariaIsabel_Jociles_Rubio.html) Consulta: 26-92014.

KIMMEL, Michael. Homofobia, temor, vergüenza y silencio en la identidad masculina. En Valdés, Teresa y Olavarría, José (Eds.): Ediciones de las Mujeres 24. Masculinidad/es. Poder y crisis. Santiago de Chile, Isis Internacional-Flacso Chile, 1997, pp. 49-62

LÓPEZ VÁZQUEZ, Belén. «El hombre atrapado en su imagen». Revista Internacional Comunicación Audiovisual, Publicidad y Estudios culturales, 2005, 3, 175186

(www.revistacomunicacion.org/pdf/n3/articulos/el_hombre_atrapado_en_su_imag en.pdf) Consulta: 23-9-2014.

PIJAMA SURF (Parentesis.com). Masculinidad tradicional: estereotipos y publicidad (pijamasurf.com/2014/04/masculinidad-tradicional-estereotipos-y-publicidad/) Consulta: 19-9-2014.

RETICO, Alessandra. «Metrosexual ganó el premio a la mejor palabra de 2003». Clarín, 2004, 15/01, 36.

REY, Juan: El hombre fingido. La representación de la masculinidad en el discurso publicitario. Madrid, Fundamentos, 1994, 240 págs.

REY, Juan. «Los "metrosexuales” y “übersexuales” como artefactos publicitarios». Revista Comunicar, 2006, 27, 19-27 (www.redalyc.org/articulo.oa?id=15802704) Consulta: 28-9-2014.

REY, Juan. La imagen del hombre en publicidad: géneros híbridos y nuevos consumidores. Ponencia en Congènere: la representació de gènere a la publicitat del segle XXI. Congreso Internacional organizado por la Universitat de Girona. Giro$\begin{array}{lllllll}\text { na, } & 25 & \text { y } & 26 & \text { mayo } & \text { de } & 2009\end{array}$ (www3.udg.edu/publicacions/vell/electroniques/congenere/comunicacions/pdf/19_ laimagen_del_hombre.pdf) Consulta: 25-9-2014.

ROJAS MARCOS, Luis. Semillas y antídotos de la violencia en la intimidad. En Obra Social "la Caixa” (Eds.): Violencia: Tolerancia cero. Barcelona, Fundación Obra Social La Caixa, 2005, pp. 89-125.

ROJAS, Enrique: El hombre light. Una vida sin valores. Madrid, Temas de hoy, 1998, 181 págs.

SÁEZ BUENAVENTURa, Carmen. Violencia y proceso de socialización genérica; enajenación y transgresión, dos alternativas extremas para las mujeres. En Maquieira, V. y Sánchez, C. (comp.): Violencia y sociedad patriarcal. Madrid, Editorial Pablo Iglesias, 1990, pp. 1-15.

SIMPSON, Mark. «Meet the metrosexual». Salon.com, 2002, 22/06.

NIKE FOOTBALL (2010). Spot de la campaña "El adversario de Cristiano". (2010). Consultado el 27 de septiembre de 2014 en www.youtube.com/watch?v=kuN1yO_wL4I\&feature=relmfu. 
TOYOTA YARIS (2005). Spot de la campaña “Espejos” (2005). Agencia DDB El Salvador. Consultado el 27 de septiembre de 2014 en https://www.youtube.com/watch?v=q1YkSffWj_0\%20.

PEPSI (2004). Spot de la campaña internacional de Pepsi "Foot battle”. (2004). Agencia CLM BBDO Consultado el 27 de septiembre de 2014 en www.youtube.com/watch?feature=player_detailpage\&v=Z7UbK24ZPc0.

TÉLLEZ, Anastasia y VERDÚ, Ana Dolores. «El significado de la masculinidad para el análisis social». Revista Nuevas Tendencias en Antropología, 2011, 2, 80 103. Consultado el 26 de septiembre de 2014 en www.revistadeantropologia.es/Textos/N2/El\%20significado\%20de\%20la\%20mas culinidad.pdf.

WORLD HEALTH ORGANIZATION. What do we mean by "sex" and "gender"? Nueva York, World Health Organization, 2010 (www.who.int/gender/whatisgender/en/) Consulta: 27-9-2014.

40PRINCIPALES. Lumbersexual: Llega el auténtico hombre de pelo en pecho (http://los40.com/los40/2014/11/24/tendencias/1416847926_755734.html) Consulta: 26-11-2014. 